\title{
The use of stable isotope probing to identify key iron-reducing microorganisms involved in anaerobic benzene degradation
}

\author{
Umakanth Kunapuli, Tillmann Lueders and Rainer U Meckenstock \\ GSF-National Research Center for Environment and Health, Institute of Groundwater Ecology, Neuherberg, \\ Germany
}

\begin{abstract}
Here, we present a detailed functional and phylogenetic characterization of an iron-reducing enrichment culture maintained in our lab with benzene as sole carbon and energy source. We used DNA-stable isotope probing to identify microbes within the enrichment most active in the assimilation of ${ }^{13} \mathrm{C}$-label. When ${ }^{12} \mathrm{C}_{6}$ - and ${ }^{13} \mathrm{C}_{6}$-benzene were added as comparative substrates, marked differences in the quantitative buoyant density distribution became apparent especially for uncultured microbes within the Gram-positive Peptococcaceae, closely related to environmental clones retrieved from contaminated aquifers world wide and only distantly related to cultured representatives of the genus Thermincola. Prominent among the other constituents of the enrichment were uncultured Deltaproteobacteria, as well as members of the Actinobacteria. Although their presence within the enrichment seems to be stable they did not assimilate ${ }^{13} \mathrm{C}$-label as significantly as the Clostridia within the time course of our experiment. We hypothesize that benzene degradation in our enrichment involves an unusual syntrophy, where members of the Clostridia primarily oxidize benzene. Electrons from the contaminant are both directly transferred to ferric iron by the primary oxidizers, but also partially shared with the Desulfobulbaceae as syntrophic partners. Alternatively, electrons may also be quantitatively transferred to the partners, which then reduce the ferric iron. Thus our results provide evidence for the importance of a novel clade of Gram-positive iron-reducers in anaerobic benzene degradation, and a role of syntrophic interactions in this process. These findings shed a totally new light on the factors controlling benzene degradation in anaerobic contaminated environments.
\end{abstract}

The ISME Journal (2007) 1, 643-653; doi:10.1038/ismej.2007.73; published online 13 September 2007

Subject Category: microbial ecology and functional diversity of natural habitats

Keywords: anaerobic benzene degradation; iron-reducing microorganisms; stable isotope probing; syntrophic interactions

\section{Introduction}

The degradation of aromatic hydrocarbons by aquifer microbial communities has caused significant scientific interest due to the high solubility and mobility of these compounds resulting in aquifer contamination and the impairment of valuable groundwater resources. A considerable diversity of microorganisms is available in pure culture that can degrade most aromatic hydrocarbons under anaerobic conditions (Heider et al., 1998; Chakraborty and Coates, 2004; Meckenstock et al., 2004). Benzene has caused the most concern since it is known to be a potential human carcinogen (Dean, 1985) and the factors that control its degradation especially in

Correspondence: RU Meckenstock, GSF-National Research Center for Environment and Health, Institute for Groundwater Ecology, Ingolstädter landstraße 1, Neuherberg 85764, Germany.

E-mail: rainer.meckenstock@gsf.de

Received 9 May 2007; revised 26 July 2007; accepted 28 July 2007; published online 13 September 2007 anaerobic environments are still poorly understood. Aerobic degradation of benzene is well studied and also several reports are available on anaerobic benzene degradation under denitrifying (Burland and Edwards, 1999), sulfate-reducing (Lovley et al., 1995; Phelps and Young, 1999), iron-reducing (Kazumi et al., 1997; Anderson et al., 1998; Jahn et al., 2005) and methanogenic conditions (Weiner and Lovley, 1998).

Benzene degradation studies with aquifer sediments under iron-reducing conditions demonstrated that members of the family Geobacteraceae were substantially enriched (Rooney-Varga et al., 1999). Comparatively, molecular characterization of a benzene-degrading, sulfate-reducing enrichment culture revealed the presence of members of the Desulfobacteraceae, a known family of aromatic hydrocarbon degraders (Phelps et al., 1998). Furthermore, physiological and molecular characterization of anaerobic benzene-degrading, methanogenic and denitrifying enrichments showed the 
presence of diverse microbes, but, similar to the above reports, failed to identify the active microbes actually responsible for benzene degradation (Ulrich and Edwards, 2003). Nevertheless, to date several facultative anaerobic strains of the genera Dechloromonas and Azoarcus were isolated, which degraded benzene under denitrifying conditions (Coates et al., 2001b; Kasai et al., 2006). However, no strictly anaerobic microbe or microbial lineage was specifically identified to degrade benzene, despite the importance of these processes in contaminated groundwater environments.

In our laboratory, we have successfully obtained a stable benzene-degrading, iron-reducing enrichment culture and maintained it for a number of years now. However, we have failed to recover single microbial isolates from this culture while maintaining benzene degradation activity. One possible reason for this lack of success may be an inadequate mimicking of in situ growth requirements during isolation, which has motivated us to apply a culture-independent technique, nucleic acid-based stable isotope probing (SIP) for the identification of key microbes involved in degradation. SIP involves the incorporation of ${ }^{13} \mathrm{C}$-label into cellular biomarkers such as nucleic acids, followed by density gradient separation of labeled nucleic acids and molecular identification of the involved microbes (Radajewski et al., 2000). Today, the SIP technique has greatly increased our understanding of the role of specific microbial community members in diverse environmental settings (Madsen, 2006) and identified key microbes utilizing various aromatic and chlorinated hydrocarbons (Manefield et al., 2002; Jeon et al., 2003; Padmanabhan et al., 2003; Mahmood et al., 2005; Yu and Chu, 2005; Kasai et al., 2006). The goal of the present study was to identify the microorganisms in our enrichment specifically responsible for anaerobic benzene degradation. Our results provide evidence for the importance of an uncultured Grampositive lineage in benzene degradation under iron reduction and a simultaneous involvement of other phylogenetic groups in apparent syntrophic interactions during degradation.

\section{Materials and methods}

Enrichment culture, growth conditions and SIP incubation

An anaerobic benzene-degrading, iron-reducing culture enriched with benzene as growth substrate and with ferrihydrite as the electron acceptor was obtained from soil of a former coal gasification site in Gliwice, Poland (U Kunapuli, C Griebler, HR Beller and RU Meckenstock, unpublished results), and was used as inoculum for SIP incubations. The culture was cultivated in $120-\mathrm{ml}$ serum bottles that were filled up to $60-\mathrm{ml}$ with bicarbonate-buffered (30 mM) freshwater mineral medium ( $\mathrm{pH} 7.2)$ at $30{ }^{\circ} \mathrm{C}$ (Widdel and Bak, 1992). The medium was prepared under an atmosphere of $\mathrm{N}_{2} / \mathrm{CO}_{2}(80 / 20$, $\mathrm{V} \mathrm{v}^{-1}$ ) and reduced with $0.5 \mathrm{mM} \mathrm{Na}_{2} \mathrm{~S}$. Amorphous iron oxide $\left[\mathrm{Fe}(\mathrm{OH})_{3}\right], 50 \mathrm{~mm}$ (Lovley and Phillips, 1986), was added as sole electron acceptor to the sulfate-free medium. ${ }^{13} \mathrm{C}_{6}$-benzene and ${ }^{12} \mathrm{C}_{6}$-benzene were added by injecting $5 \mu \mathrm{l}$ of pure compound through butyl rubber stoppers with a gastight syringe (Hamilton Co) giving a final benzene concentration of approx $900 \mu \mathrm{M}$ aqueous concentration. $10 \%$ of homogenized inoculum was injected into each serum bottle for the initiation of the SIP experiment. Samples for $\mathrm{CO}_{2}$ and ferrous iron measurement were taken weekly and replicate bottles were subsequently sacrificed for nucleic acid extraction at 38, 60, 66, 91, 119 days of incubation. ${ }^{13} \mathrm{C}_{6}$-benzene was chemically produced as described elsewhere (Eichinger et al., 1980). Strict anaerobic conditions were employed during cultivation. Increase of ferrous iron over time was monitored by the ferrozine assay (Stookey, 1970).

\section{GC-C-IRMS analyses}

The GC-C-IRMS analyses system consisted of a TRACE GC ultra gas chromatograph (Thermo Fisher Scientific Corporation, Milan, Italy), which was coupled to a Finnigan MAT 253 isotope ratio mass spectrometer (IRMS) (Thermo Fisher Scientific Corporation, Bremen, Germany) via a Finnigan GC Combustion III interface (Thermo Fisher Scientific Corporation, Bremen, Germany). The GC was equipped with (i) an Optic 3 temperature programmable high performance injector system of ATAS GL International B V (Veldhoven, The Netherlands) and (ii) a Rt-QPLOT column $(30-\mathrm{m} \times 0.32-\mathrm{mm}$; Restek Corp, Bellefonte, PA, USA), to which deactivated fused-silica pre- and post-columns were attached (FS-Methyl-Sil, 3-m $\times 0.32-\mathrm{mm}$ and $2-\mathrm{m} \times 0.32-\mathrm{mm}$, respectively; CS Chromatographie Service $\mathrm{GmbH}$, Langerwehe, Germany). Split flow of the Optic 3 injector was set to $14 \mathrm{ml} \mathrm{min}^{-1}$, that is split-ratio of 1:10 and temperature held isothermally at $40^{\circ} \mathrm{C}$. The GC temperature program was isothermal at $40^{\circ} \mathrm{C}$. Helium of grade 5.0 was used as carrier gas with a constant flow rate of $1.4 \mathrm{ml} \mathrm{min}^{-1}$. The carbon isotopic composition of $\mathrm{CO}_{2}$ is reported in the $\delta$-notation relative to Vienna PeeDee Belemnite (V-PDB).

$$
\begin{aligned}
\delta^{13} \mathrm{C}= & {\left[\left({ }^{13} \mathrm{C} /{ }^{12} \mathrm{C}_{\text {Sample }}-{ }^{13} \mathrm{C} /{ }^{12} \mathrm{C}_{\mathrm{V}-\text { PDB Standard }}\right)\right.} \\
& \left./{ }^{13} \mathrm{C} /{ }^{12} \mathrm{C}_{\text {V-PDB Standard }}\right] \times 1000
\end{aligned}
$$

$$
\begin{aligned}
& \text { Total }{ }^{13} \mathrm{CO}_{2} /{ }^{12} \mathrm{CO}_{2} \text { Sample } \\
& \quad=\left[1+\delta^{13} \mathrm{CO}_{2} / 1000\right] \times\left[{ }^{13} \mathrm{CO}_{2} /{ }^{12} \mathrm{CO}_{2} \text { V-PDB Standard }\right]
\end{aligned}
$$

$$
\begin{aligned}
&{ }^{13} \mathrm{CO}_{2}[\mathrm{mM}]={ }^{13} \mathrm{CO}_{2} /{ }^{12} \mathrm{CO}_{2} \text { Sample } \\
& \times \text { initial } \mathrm{CO}_{2}[\mathrm{mM}]
\end{aligned}
$$


Initial ${ }^{12} \mathrm{CO}_{2}$ concentration is the sum of ${ }^{12} \mathrm{CO}_{2}$ concentration from $\mathrm{NaHCO}_{3}$ buffer in the liquid phase and $20 \%$ of $\mathrm{CO}_{2}$ gas in the headspace of the culture bottles.

Analyte gases were measured against a laboratory $\mathrm{CO}_{2}$ reference gas that was calibrated to V-PDB by referenced $\mathrm{CO}_{2}$ isotope standards (RM 8562, RM 8563, RM 8564) provided by the International Atomic Energy Agency (IAEA, Vienna). Samples for GC-C-IRMS measurement were taken from the headspace of the serum bottles using a microliter syringe (Hamilton Co.) and $10 \mu \mathrm{l}$ was directly injected for analysis.

\section{Nucleic acid extraction and density-gradient} centrifugation

After sacrificing bottles at successive time points of the experiment, DNA was extracted from collected cell pellets (centrifuged at 4000 r.p.m. at $4{ }^{\circ} \mathrm{C}$ for 5 min, Megafuge 1.0. R, Heraeus Instruments, Osterode, Germany) of culture as described previously (Lueders et al., 2004). Nucleic acid extracts were checked for quality by standard agarose gel electrophoresis and ethidium-bromide staining. Densitygradient centrifugation was performed in $5 \mathrm{ml}$ polyallomer quick seal tubes in a VTI 65.2 vertical rotor (both Beckman) using a Centrikon T-2190 centrifuge (Kontron Instruments, Milano, Italy). Centrifugation was done at $20^{\circ} \mathrm{C}$ for $>36 \mathrm{~h}$ at 45000 r.p.m. (184 $000 \mathrm{~g}$ ). The preparation of gradient buffer and CsCl (VWR Scientific, Darmstadt, Germany) centrifugation media with an average density of $\sim 1.72 \mathrm{~g} \mathrm{ml}^{-1}$ was done as described previously (Lueders et al., 2004). Approximately $500 \mathrm{ng}$ of DNA was loaded for each gradient and centrifuged gradients were fractionated into 12 equal fractions $(400 \mu \mathrm{l})$ from bottom to top by displacement with water from the top using an infusion syringe pump at a flow rate of $1 \mathrm{mlmin}^{-1}$. Density of each gradient fraction was determined using an AR200 digital refractometer (Reichert Inc., Depew, NY, USA) and fraction aliquots of $75 \mu \mathrm{l}$. DNA was retrieved from each gradient fraction with polyethylene glycol precipitation, washed in $70 \%$ ethanol and re-eluted in $30 \mu \mathrm{l}$ elution buffer (Qiagen, Hilden, Germany).

\section{Quantification of rRNA genes in the density gradient fractions}

Bacterial 16S rRNA genes were quantified specifically from the precipitated density gradient fractions using primer set Ba519f/907r by real-time PCR in an Mx3000P cycler (Stratagene, La Jolla, CA, USA) as described previously (Lueders et al., 2004). Each $50 \mu \mathrm{l}$ PCR reaction mixture contained of $1 \times$ PCR buffer, $1.5 \mathrm{mM} \mathrm{MgCl}_{2}, 1.25 \mathrm{U}$ Taq DNA polymerase, $0.1 \mathrm{mM}$ dNTPs (all MBI Fermentas, St Leon-Rot, Germany), $10 \mu \mathrm{g}$ BSA (Roche, Mannheim, Germany), $0.1 \times$ SybrGreen and ROX dyes (FMC
Bioproducts, Oldendorf, Germany), $0.25 \mu \mathrm{M}$ of each primer, and $2 \mu \mathrm{l}$ of DNA template. The thermal protocol consisted of an initial denaturation $\left(94^{\circ} \mathrm{C}\right.$, 3 min), 40 cycles of amplification $\left(94^{\circ} \mathrm{C}, 30 \mathrm{~s} ; 52^{\circ} \mathrm{C}\right.$, $\left.30 \mathrm{~s} ; 70{ }^{\circ} \mathrm{C}, 30 \mathrm{~s}\right)$ and a terminal extension step $\left(72^{\circ} \mathrm{C}\right.$, $5 \mathrm{~min}$ ). Bacterial $16 \mathrm{~S}$ rRNA gene quantities were standardized using almost full-length amplicons of the E. coli $16 \mathrm{~S}$ rRNA genes in concentrations between $10^{7}$ and $10^{0}$ copies $\mu \mathrm{l}^{-1}$.

\section{Fingerprinting analyses}

Terminal restriction fragment length polymorphism (T-RFLP) fingerprinting of density-resolved DNA fractions was done with primers Ba27f-FAM and 907r; labeled amplicons were digested with MspI and size separated on a ABI 3730 DNA analyzer, all as described previously (Lueders et al., 2006).

\section{Cloning and sequencing analyses}

Almost full-length bacterial 16S rRNA gene fragments were amplified from precipitated DNA centrifugation gradients with primers Ba27f and Ba1492r (Weisburg et al., 1991). The resulting PCR products were cloned and sequenced, and the sequence data were assembled to contigs as described previously (Winderl et al., 2007). Closely related 16S rRNA sequences were identified using BlastN search program (http://ncbi.nlm.nih.gov/ BLAST). The aligned sequences ( $\sim 1450 \mathrm{bp})$ were integrated into ARB 16S rRNA database for phylogenetic analyses (Ludwig et al., 2004). To evaluate treeing topology, phylogenetic dendrograms of the 16S rRNA gene sequences were visualized using distance matrix, neighbor-joining, maximum likelihood and treepuzzle methods as implemented in ARB. A phylogenetic tree reconstructed by maximum likelihood algorithms (fastDNAml) using a $50 \%$ base frequency filter was consistent with the branching order of all other tree reconstructions and was selected for presentation. All 16S rRNA gene clone sequences from this study were deposited with GenBank under the accession nos. EU016408EU016450.

\section{Results}

Enrichment culture and incubation with ${ }^{13} C_{6}$-benzene The benzene-degrading, iron-reducing enrichment culture used in this study was obtained from soil of a former coal gasification site in Gliwice, Poland. It completely mineralizes benzene to $\mathrm{CO}_{2}$ coupled to iron reduction (U Kunapuli, C Griebler, HR Beller and RU Meckenstock, unpublished results). The culture has been frequently transferred into freshwater mineral medium until a stable sediment-free enrichment was obtained.

To monitor the community composition of the enrichment culture, T-RFLP fingerprinting was performed at various time points during enrichment 


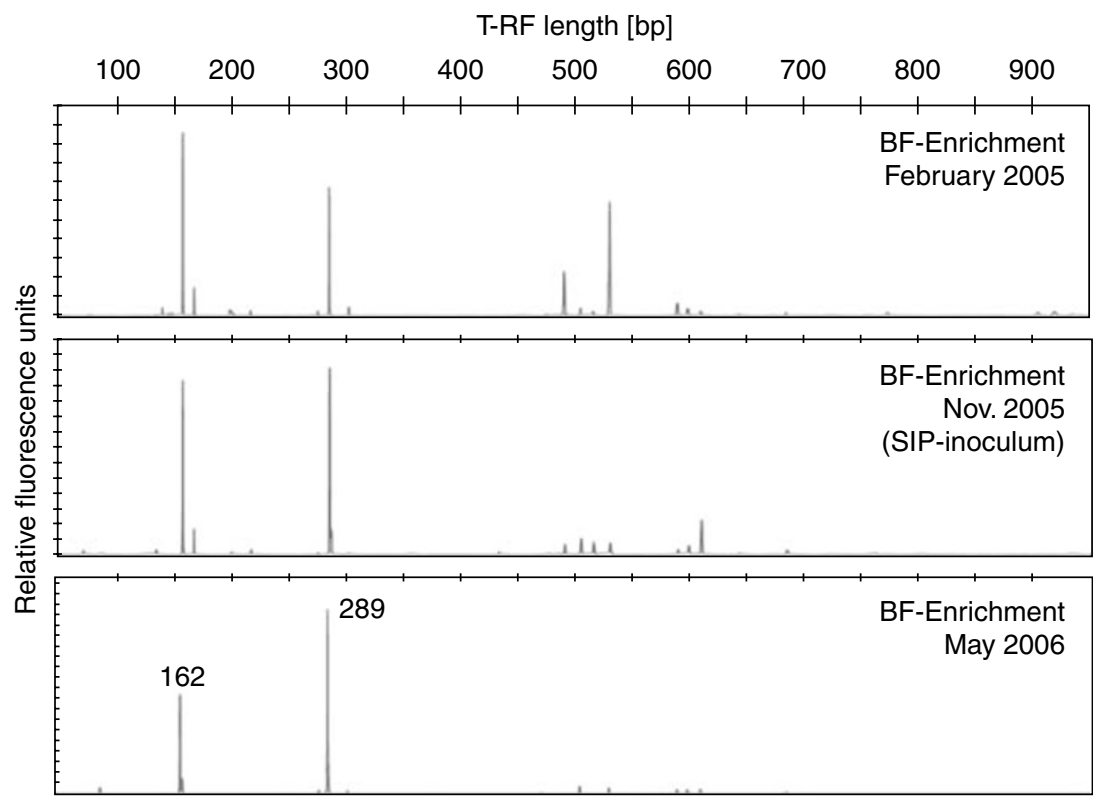

Figure 1 Temporal dynamics of the bacterial community within our iron-reducing, benzene-degrading enrichment culture during successive transfers and stages of enrichment as monitored by terminal restriction fragment-length polymorphism fingerprinting analyses of bacterial 16S rRNA genes. 'BF'-benzene-ferrihydrite enrichment.

to visualize diversity changes (Figure 1). The communal composition showed temporal variation during the course of enrichment and subsequent transfers. The diversity of T-RFs within the ironreducing enrichment culture decreased with time and was eventually represented by two major T-RFs that gained dominance over others initially present. The dominant T-RFs were identified as 289 and $162 \mathrm{bp}$ respectively, although several other T-RFs were observed in the early stages of enrichment. To characterize the microbes represented by both T-RFs (289 and $162 \mathrm{bp}$ ) and to gain further insights into their specific functions in benzene degradation, we performed SIP on the iron-reducing enrichment culture.

When the culture was incubated with ${ }^{13} \mathrm{C}_{6}$ benzene as the growth substrate, a clear increase in the ${ }^{13} \mathrm{CO}_{2}$ (mM) produced during growth was observed indicating the utilization of the provided substrate by the culture (Figure 2a). The utilization of benzene as the growth substrate was also monitored by measuring the amount of ferrous iron produced concomitantly from the reduction of ferric iron as terminal electron acceptor (Figure 2b). From $\sim 0.9 \mathrm{mM}$ of ${ }^{13} \mathrm{C}$-benzene added to the bottles, $\sim 4.78 \mathrm{mM}{ }^{13} \mathrm{CO}_{2}$ (Equations (1-3)) and $20.5 \mathrm{mM}$ $\mathrm{Fe}(\mathrm{II})$ were produced after 120 days (Figures 2a and $b)$. According to the stoichiometric oxidation of benzene to $\mathrm{CO}_{2}$ (Equation (4)), this corresponds to $0.80 \mathrm{mM}$ of ${ }^{13} \mathrm{C}$-benzene that were oxidized and $\sim 85 \%$ of electrons recovered in the ferrous iron produced which clearly substantiates iron-dependent benzene oxidation. The evolved ${ }^{13} \mathrm{CO}_{2}$ concentration from benzene mineralization was normalized
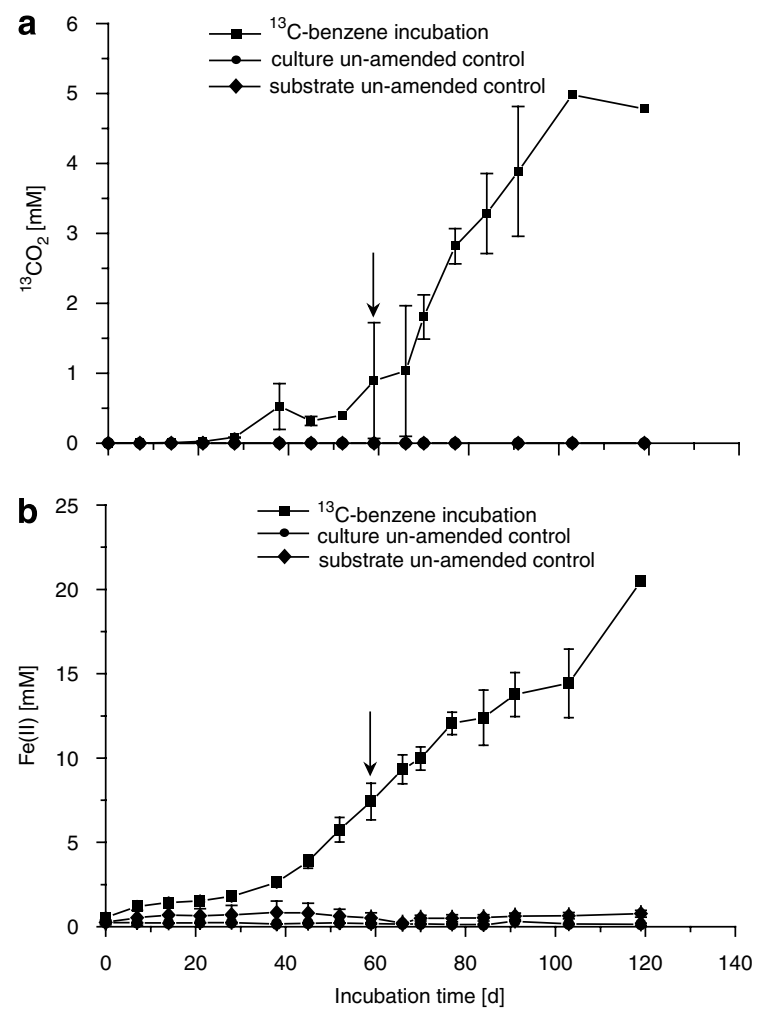

Figure 2 Time course of (a) ${ }^{13} \mathrm{CO}_{2}$-evolution during degradation of ${ }^{13} \mathrm{C}$-benzene in experimental controls, and culture un-amended and substrate un-amended controls. (b) Formation of Fe(II) during growth of the enrichment on ${ }^{13} \mathrm{C}$-benzene, as well as in culture un-amended and substrate un-amended controls. Arrows indicate the days of sampling for stable isotope probinganalysis. Vertical bars represent standard errors of duplicate or triplicate measurements. 
to the initial ${ }^{13} \mathrm{CO}_{2}$ present in the serum bottle (0.42 mM) coming from the bicarbonate buffer.

$$
\begin{aligned}
\mathrm{C}_{6} \mathrm{H}_{6}+30 \mathrm{Fe}(\mathrm{OH})_{3} \rightarrow & 6 \mathrm{HCO}_{3}^{-}+30 \mathrm{Fe}^{(\mathrm{II})}+18 \mathrm{H}_{2} \mathrm{O} \\
& +54 \mathrm{OH}^{-}
\end{aligned}
$$

No increase in the ${ }^{13} \mathrm{CO}_{2}$ concentration and no increase in ferrous iron concentration were observed in the substrate un-amended and culture unamended controls.

Quantitative and qualitative analysis of comparative SIP gradients

Sacrificed bottles from the ${ }^{13} \mathrm{C}_{6}$ - and ${ }^{12} \mathrm{C}_{6}$-benzene incubations from various time points were taken for gradient centrifugation after DNA extraction. A 60day time point from ${ }^{13} \mathrm{C}$ - and ${ }^{12} \mathrm{C}$-labeled incubations was chosen for further study, which was an early time point in terms of formed ${ }^{13} \mathrm{CO}_{2}$, and thus bore the potential to truly unravel distinctions in label allocation to the different consortium members. After centrifugation, the gradients were fractionated into 12 equal aliquots and quantitative PCR (qPCR) was used to quantify the abundance of bacterial $16 \mathrm{~S}$ rRNA gene copies present in each individual fraction, and to assess comparative template distribution in the ${ }^{12} \mathrm{C}$ - and ${ }^{13} \mathrm{C}$-gradients (Figure $3 \mathrm{a}$ ).

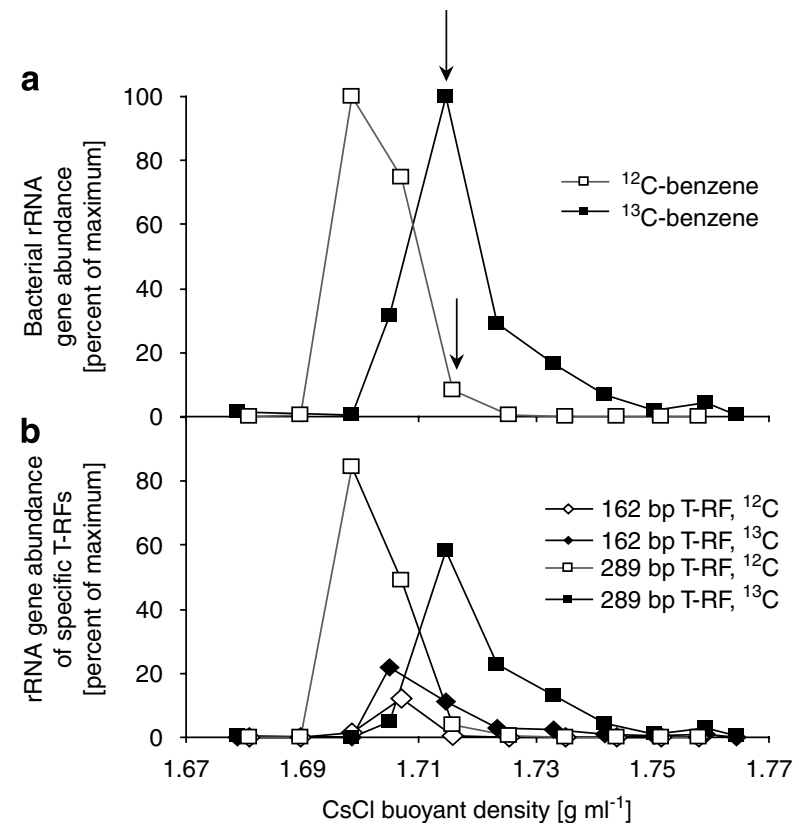

Figure 3 Quantitative profiles of gene distribution in comparative $\mathrm{CsCl}$ density-gradient centrifugations of DNA extracted from benzene-degrading, iron-reducing enrichments inoculated with either ${ }^{13} \mathrm{C}_{6}$-benzene or ${ }^{12} \mathrm{C}_{6}$-benzene. (a) Distribution of bacterial 16S rRNA genes within density gradient fractions as quantified by real-time PCR. (b) Quantitative T-RF abundance distribution as calculated by multiplying total gene abundance (Figure 3a) by the relative T-RF peak height abundance of fingerprints for all fractions. Arrows indicate the gradient fractions selected for cloning and sequencing analyses.
Quantitative label incorporation was very evident in the ${ }^{13} \mathrm{C}$-labeled gradient, where the peak of bulk DNA shifted to a buoyant density (BD) of $1.715 \mathrm{~g} \mathrm{ml}^{-1}$ compared to that of the ${ }^{12} \mathrm{C}$-gradient $\left(1.698 \mathrm{~g} \mathrm{ml}^{-1}\right)$. This shift in BD of $\sim 0.02 \mathrm{~g} \mathrm{ml}^{-1}$ corresponds to $\sim 50 \%$ of the density shift of $\sim 0.04 \mathrm{~g} \mathrm{ml}^{-1}$ expected for $100 \%$ label incorporation (Lueders et al., 2004). But also a tailing of DNA into even heavier fractions, indicating higher label incorporation for the part of genomes, was detected in the ${ }^{13} \mathrm{C}$-gradient.

T-RFLP fingerprints of the density-resolved communities were generated from all gradient fractions, to identify the specific community members most efficient in label incorporation. The selection of an 'early' time point is especially important in an enrichment culture with a strongly reduced diversity compared to environmental samples and an assemblage of microbes that will sooner or later incorporate carbon from the added benzene either directly or via trophic cross-feeding. Again, in all fractions the community was dominated by the 162 and $289 \mathrm{bp}$ T-RFs, but several other T-RFs such as the $80,145,165$ and 225 bp T-RFs where detected in some fractions (Figure 4). However, their contribution to the total T-RF abundance was low, especially when normalized to total peak abundance. To further unravel label allocation to the major T-RFs, we multiplied relative total gene abundance (as plotted in Figure 3a) by the relative T-RF peak height abundance within fingerprints for all fractions, thus facilitating a comparative assessment of quantitative T-RF abundance distribution between the ${ }^{12} \mathrm{C}$ - and ${ }^{13} \mathrm{C}$ gradients (Figure $3 \mathrm{~b}$ ). This clearly showed that the microbes represented by the $289 \mathrm{bp}$ T-RF received most of the ${ }^{13} \mathrm{C}$-label. At the same time the density distribution of the $162 \mathrm{bp}$ T-RF remained almost constant, with maximum frequencies always at $\sim 1.705 \mathrm{~g} \mathrm{ml}^{-1}$. Nevertheless, fingerprinting showed a clear distinction in T-RF allocation between the ${ }^{12} \mathrm{C}$ - and the ${ }^{13} \mathrm{C}$-gradients, which was, however, more evident in the light fractions rather than in the heavy fractions (Figure 4).

\section{Phylogenetic identification of labeled and unlabeled community components}

The specific microbial community members represented by the detected T-RFs within 'light' and 'heavy' DNA were subsequently identified by cloning and sequencing. Two independent clone libraries were constructed from one gradient fraction each of the ${ }^{12} \mathrm{C}$ - and ${ }^{13} \mathrm{C}$-centrifugation gradients, respectively. The two fractions chosen for cloning were as follows: Gradient fractions HS07 (BD $1.715 \mathrm{~g} \mathrm{ml}^{-1}$ ) that is the fraction containing the bulk of labeled DNA in the ${ }^{13} \mathrm{C}$-treatment and a fraction of similar $\mathrm{BD}$ in the ${ }^{12} \mathrm{C}$-treatment, HT06 (BD $1.716 \mathrm{~g} \mathrm{ml}^{-1}$ ), containing additional low-frequency T-RFs at 80 and $165 \mathrm{bp}$ (see also Figures 3 and 4). The $16 \mathrm{~S}$ rRNA gene clones from the ${ }^{13} \mathrm{C}_{6}$-benzene 
T-RF length $[\mathrm{bp}]$
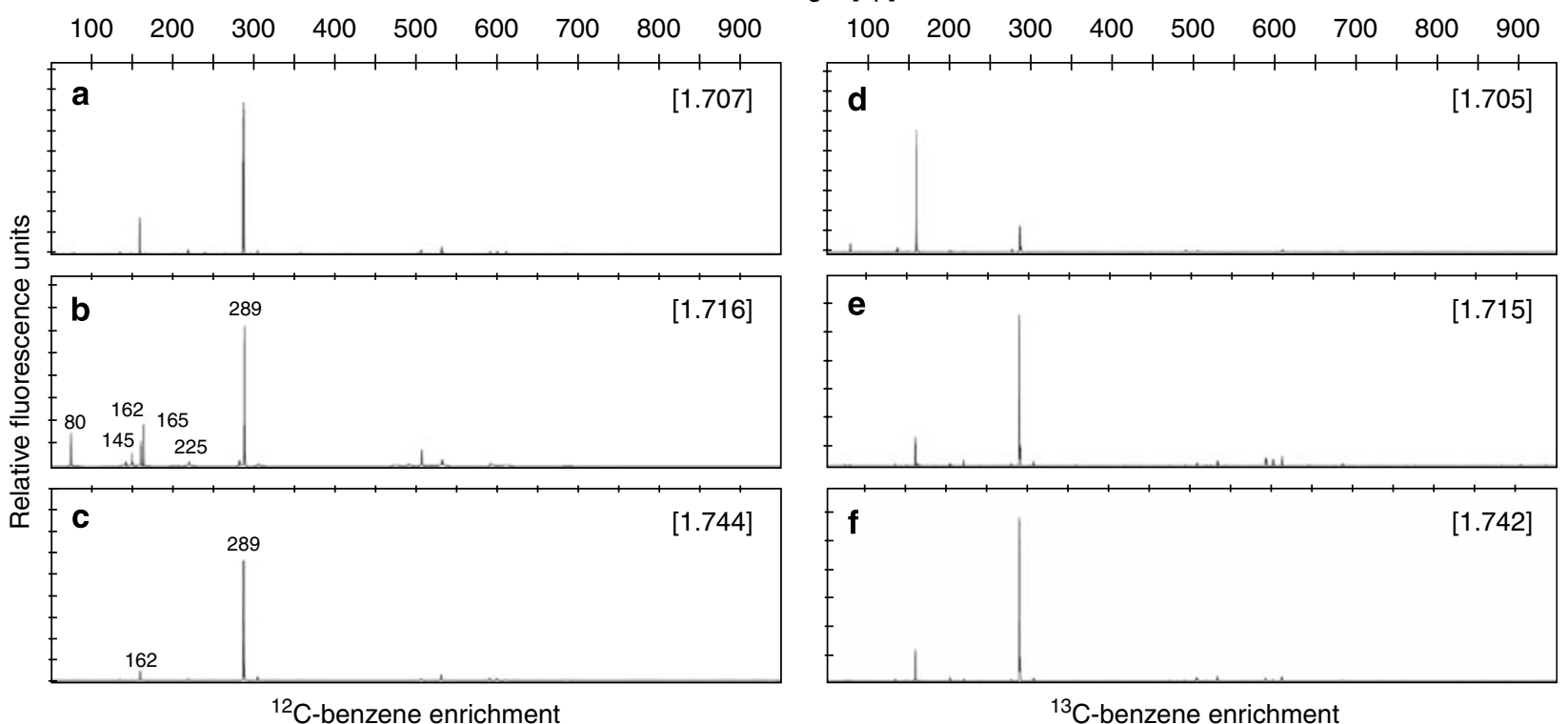

Figure 4 Terminal restriction fragment-length polymorphism fingerprinting of density resolved fractions obtained from stable isotope probing gradients of ${ }^{12} \mathrm{C}_{6}$-benzene $(\mathbf{a}, \mathbf{b}, \mathbf{c})$ and ${ }^{13} \mathrm{C}_{6}$-benzene (d, e, f) gradients. Numbers in parentheses represent buoyant densities $\left(\mathrm{g} \mathrm{ml}^{-1}\right)$. Fingerprints $\mathbf{b}$ and $\mathbf{e}$ were selected for $16 \mathrm{~S}$ rRNA gene sequencing.

Table 1 Phylogenetic affiliation of bacterial 16S rRNA clone sequences from ${ }^{13} \mathrm{C}_{6}$-benzene and ${ }^{12} \mathrm{C}_{6}$-benzene enrichments generated from SIP density-gradient fractions

\begin{tabular}{|c|c|c|c|}
\hline \multirow{2}{*}{$\begin{array}{l}\text { Phylogenetic } \\
\text { affiliation }\end{array}$} & \multicolumn{2}{|c|}{ No. of clones } & \multirow{2}{*}{$\begin{array}{c}\text { Charac- } \\
\text { teristic } \\
T-R F(b p)^{\mathrm{a}}\end{array}$} \\
\hline & $\begin{array}{c}{ }^{13} C_{6} \text {-Benzene } \\
\text { enrichment } \\
\text { (HSo7Ba- } \\
\text { library) }\end{array}$ & $\begin{array}{c}{ }^{12} C_{6}-\text { Benzene } \\
\text { enrichment } \\
\text { (HTo6Ba- } \\
\text { library) }\end{array}$ & \\
\hline \multicolumn{4}{|l|}{ Deltaproteobacteria } \\
\hline Desulfobulbaceae & 3 & 5 & 162 \\
\hline \multicolumn{4}{|l|}{ Clostridia } \\
\hline $\begin{array}{l}\text { Uncultured cluster } \\
\text { BF1 }\end{array}$ & 11 & 4 & 289 \\
\hline Other uncultured & 1 & - & NA \\
\hline Moorella-related & 2 & 1 & 225 \\
\hline \multicolumn{4}{|l|}{ Actinobacteria } \\
\hline Actinotalea-related & - & 5 & 165 \\
\hline $\begin{array}{l}\text { Cellulomonas- } \\
\text { related }\end{array}$ & - & 3 & 80 \\
\hline Terrabacter-related & - & 2 & 145 \\
\hline Isoptericola-related & - & 1 & 145 \\
\hline Chloroflexi & 1 & 1 & NA \\
\hline Other proteobacteria & 1 & 1 & NA \\
\hline
\end{tabular}

Abbreviation: NA, not applicable; SIP, stable isotope probing. ${ }^{a}$ T-RFs conserved for all clones of a lineage.

incubation ( $n=18$, see Table 1$)$ formed two major clusters within the Clostridia (Peptococcaceae) and the Deltaproteobacteria (Desulfobulbaceae). Sequence data predicted that the clostridial clone cluster, which we provisionally named 'BF1-cluster', was all represented within the $289 \mathrm{bp}$ T-RF, while the $162 \mathrm{bp}$ fragment correlated to the uncul- tured Desulfobulbaceae. Closest relatives for these two clusters are all environmental clones retrieved directly from contaminated aquifers or other contaminant-degrading systems worldwide (Figure 5). In this library, we also detected two clones related to the clostridial Moorella spp.

This library assembly was in sharp contrast to the composition of the library from the corresponding ${ }^{12} \mathrm{C}_{6}$-benzene gradient fraction (Table 1 ). Here, the uncultured Desulfobulbaceae and BF1-cluster clones were also frequent constituents (five and four clones, respectively), but most strikingly, a high frequency (almost 50\%) of clones within the Actinobacteria was observed. All the actinobacterial clones sequenced belonged to three major families, that is Cellulomonadaceae, Promicromonosporaceae and Intrasporangiaceae, mostly related to the genera Actinotalea, Cellulomonas and Terrabacter spp. (see Table 1). These were corresponding to the 165, 80 and $145 \mathrm{bp}$ T-RFs detected within the HT06 fraction, respectively. Furthermore, single clones within other Proteobacteria and the Chloroflexi were detected within both libraries, but they did not appear to constitute a functionally important fraction of our enrichment community.

\section{Discussion}

Here, we present an anaerobic, iron-reducing enrichment culture, which is able to utilize benzene as sole carbon and electron source. Although the culture grows within reasonable time frames of 3-4 month from a 1/10 $\left(\mathrm{v} \mathrm{v}^{-1}\right)$ inoculum, all of our attempts to obtain a pure culture by dilution to 


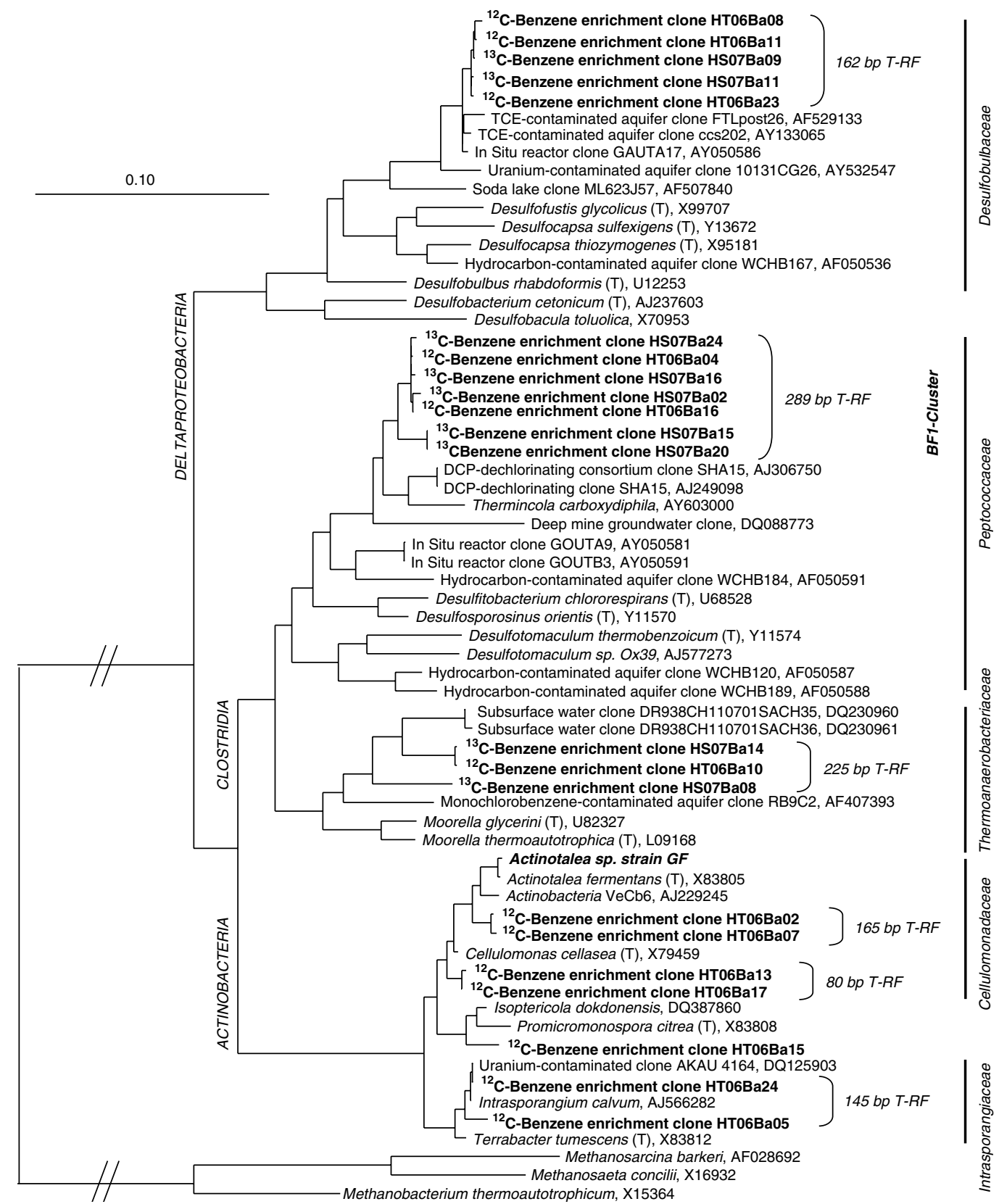

Figure 5 Phylogenetic tree showing the affiliation of representative bacterial 16S rRNA gene clones within the Deltaproteobacteria, Clostridia and the Actinobacteria as detected in clone libraries of density-gradient-resolved DNA fractions of our iron-reducing enrichment degrading either ${ }^{13} \mathrm{C}$-benzene (HS07-clones) or ${ }^{12} \mathrm{C}$-benzene (HT06-clones). Obtained clones are indicated in bold. The scale bar represents $10 \%$ sequence divergence. GenBank accession numbers of reference sequences are indicated.

extinction were without success so far. Therefore, we applied culture-independent techniques (for example SIP) to characterize the specific microbes in the consortium and their potential role in benzene utilization. Initial community screening by T-RFLP revealed a multimember microbial consortium within our benzene-degrading enrichment and SIP allowed us to identify the microbes primarily involved in the carbon assimilation. This was only possible due to the combined application of fingerprinting and qPCR analyses of the density resolved gradient fractions, which allowed us to assign label incorporation to specific T-RFs, and thus microbes.

Phylogenetic affiliation of the culture members Clones within the novel clostridial BF1-cluster represented almost $37 \%$ of our sequenced clones from the combined labeled and unlabeled densitygradient fractions. The nearest relatives are clones identified from a dichloropropane-dechlorinating 
mixed culture obtained from river sediments (Schlötelburg et al., 2000). The closest described representatives are thermophilic Thermincola carboxydiphila (92\% sequence identity), (Sokolova et al., 2005) and Thermincola ferriacetica, a facultative anaerobe capable of reducing ferric iron (Zavarzina et al., 2007). Other relatives of the BF1-cluster comprise clones obtained from an in situ reactor treating groundwater contaminated with monochlorobenzene (Alfreider et al., 2002). Further clostridial clones within our enrichment were assigned to members of the thermophilic genus Moorella, however, they clustered separately and were phylogenetically more related to subsurface aquifer clones (Collins et al., 1994; Slobodkin et al., 1997).

The second major clone cluster identified from the 16S rRNA gene sequences grouped with the deltaproteobacterial family Desulfobulbaceae, which represented nearly $20 \%$ of all the sequenced clones. The clones showed relation to various clones retrieved from diverse contaminated aquifer sites such as TCE-contaminated, uranium-contaminated, as well as in situ reactor clones monitoring monochlorobenzene degradation (Alfreider et al., 2002).

Cultivated members of the Desulfobulbaceae are mostly known to utilize several sulfur compounds as electron acceptors with members of the genus Desulfocapsa known for sulfur disproportionation (Kuever et al., 2005). Certain species were also reported to reduce ferric iron (Knoblauch et al., 1999). Moreover, a single sulfate-reducing bacterium related to Desulfocapsa was reported to anaerobically utilize toluene with sulfate as the electron acceptor (Meckenstock, 1999; Winderl et al., 2007). Whether the observed Desulfobulbaceae in our enrichment were directly reducing ferric iron, or shuttling electrons for example via a sulfide/sulfur shuttle (Straub and Schink, 2004) cannot be discerned with the present results. Although sulfate was not present in our enrichment, another option (although unlikely) might be that sulfate reducers in our enrichment utilized oxidized sulfur species that were generated by oxygen seeping through the stopper. However, the relatively high abundance of the Desulfobulbaceae and the almost closed electron balance of $85 \%$ recovery in the ferrous iron accounts against significant oxygen penetration.

The third major cluster of the entire sequenced clones (29\%) grouped with the Actinobacteria that were detected especially in the ${ }^{12} \mathrm{C}$-gradient. This can be explained by the fact that the HT06 library was generated at a density quite high for unlabeled DNA, and thus is expected to contain an overrepresentation of high $\mathrm{G}+\mathrm{C}$ genomes. The Actinobacteria in the enrichment culture could utilize secondary substrates arising from the metabolism of primary substrates and/or dead biomass. This could also explain why we obtained a pure culture (Strain GF, see Figure 5) of a member of the Actinobacteria (U Kunapuli, unpublished results) from the ben- zene-degrading enrichment selected on glucose, which is related to the recently described genus Actinotalea (Yi et al., 2007). Members of the Actinobacteria are mostly known for their aerobic mode of respiration utilizing various polysaccharides, with the exception of few members that are also known for facultative anaerobic growth.

Comparison with known benzene degraders and benzene-degrading enrichment cultures

Several reports are available which showed a particular microbial group or community under different electron-accepting conditions to be involved in anaerobic benzene degradation. Molecular characterization of a sulfate-reducing enrichment culture degrading benzene identified clones related to Cytophaga, Thiomicrospora, low G + C Grampositives and Deltaproteobacteria (Phelps et al., 1998) of which four major clones fell within the deltaproteobacterial Desulfobacteraceae, members of which are known to utilize aromatic compounds (Bak and Widdel, 1986; Szewzyk and Pfennig, 1987; Rabus et al., 1993; Beller et al., 1996).

The importance of iron-reducing microorganisms in the mineralization of benzene under anoxic conditions was reported previously wherein members of the family Geobacteraceae were shown to be the most dominant organisms (Rooney-Varga et al., 1999). Members of the family Geobacteraceae are major iron-reducing microorganisms in subsurface environments (Lonergan et al., 1996) and their prevalence in benzene-degrading sediments and enrichments is not of surprise as several species are known to degrade aromatic hydrocarbons like toluene (Lovley et al., 1993; Coates et al., 2001a). No further isolate or lineage was hypothesized to date to be involved in anaerobic benzene degradation under iron-reducing conditions. Here, we provide evidence that members of the clostridial Peptococcaceae dominate the enrichment culture expressing this activity, although we cannot directly conclude that the Clostridia were the active iron-reducers in the enrichment. Nevertheless, we clearly show that they incorporated most carbon from the contaminant, and furthermore, close relatives of the genera Desulfosporosinus and Desulfitobacterium, have been reported to reduce various forms of ferric iron (Robertson et al., 2001; Villemur et al., 2006). Our data highlight the so-far unrecognized importance of Gram-positive Peptococcaceae in anaerobic aromatic hydrocarbon degradation.

Syntrophic interactions in benzene degradation under iron reduction

Methanogenic degradation of benzene is assumed to involve syntrophic cooperation between fermentative microorganisms and methanogens. A molecular characterization of a methanogenic consortium degrading benzene showed several bacterial clones 
related to sulfate-reducing microbes such as Desulfosporosinus and Desulfobacterium and archaeal clones related to acetotrophic methanogens as well as methanogens that utilize $\mathrm{H}_{2}-\mathrm{CO}_{2}$ and formate (Ulrich and Edwards, 2003). The authors interpreted the presence of several sulfate reducers in the methanogenic consortia to be a result of a shift in the culture from sulfate reduction to methanogenesis. However, it is well known that for the transformation of non-C1 or non-C2 compounds to methane, methanogens require close syntrophic interactions with fermenters, and that sulfate reducers can fill this functional niche (Schink, 1997).

The relative abundance of cloned sequences and T-RFs from our SIP incubations showed that microbes of the uncultivated cluster within the Clostridia, that is the 'BF1-cluster' (289 bp T-RF) and uncultured members of the Desulfobulbaceae (162 bp T-RF) are the key-players within our benzene-degrading, iron-reducing enrichment culture and thus apparently both essential for this process. Therefore, we propose a syntrophic mode of interaction during anaerobic benzene degradation, which is quite unusual and has not been postulated for iron-reducing systems to date. In this interaction, the BF1-cluster seems to be responsible for the initial attack of the benzene, since it assimilates the label most efficiently, while the Desulfobulbaceae seem to be thriving primarily on the electrons stemming from the contaminant, but assimilate mostly background-carbon (that is carbonate) from the artificial groundwater medium. They do not directly assimilate label, as the $162 \mathrm{bp}$ T-RF remains mostly in 'light' fractions, also in the ${ }^{13} \mathrm{C}$-benzene gradient. Therefore, we can only speculate that the interaction between the two populations could be based on the transfer of $\mathrm{H}_{2}$, which the primary degraders release, and the secondary microbes utilize, thereby 'pulling' the initial reaction towards completion as generally established for syntrophic associations under methanogenic conditions (Schink, 1997). These data also imply that acetate or other fermentation products cannot be an important intermediate in the syntrophic partnership, otherwise also the secondary partner would become labeled. This is in contrast to the syntrophic oxidation of many compounds including fatty acids and alkanes known for methanogenic systems (Schink, 1997; Zengler et al., 1999). However, we must state that we did not determine acetate, or other intermediates that may have been formed during degradation.

While oxidizing $\mathrm{H}_{2}$, the Desulfobulbaceae could assimilate $\mathrm{CO}_{2}$, from the surrounding medium, which would explain why they are not efficiently labeled. As hypothesized above, they could then pass on part of the electrons to ferric iron either directly or indirectly via a sulfide/sulfur shuttle (Straub and Schink, 2004). It is important to note that the culture is not able to grow with benzene and sulfate as electron donor and acceptor. Therefore, iron reduction probably is the direct terminal electron accepting process for the benzene oxidation and not indirectly via a sulfate shuttle.

The other microbes detected could either carry out an acetogenic life-style (the Moorella-relatives) or ferment secondary carbohydrates or dead biomass provided by the primary syntrophs (the Actinobacteria). However, T-RFLP data showed them to be of inferior abundance within our enrichment, and thus probably not crucial for primary benzene degradation. The precise mode of syntrophic interactions within the consortium remains to be discerned. Nevertheless, this study clearly demonstrates how SIP can help to unravel the true identity and specific functions of microorganisms responsible for contaminant degradation in environmental settings and to reveal factors that may control or limit their activity in situ.

\section{Acknowledgements}

We thank Sabine Schaefer for excellent technical assistance in $16 \mathrm{~S}$ rRNA gene sequencing and Nadezda Kadlec for expert help with GC-C-IRMS analyses.

\section{References}

Alfreider A, Vogt C, Babel W. (2002). Microbial diversity in an in situ reactor system treating monochlorobenzene contaminated groundwater as revealed by $16 \mathrm{~S}$ ribosomal DNA analysis. Syst Appl Microbiol 25: 232-240.

Anderson RT, Rooney-Varga JN, Gaw CV, Lovley DR. (1998). Anaerobic benzene oxidation in the Fe(III) reduction zone of petroleum-contaminated aquifers. Environ Sci Technol 32: 1222-1229.

Bak F, Widdel F. (1986). Anaerobic degradation of phenol and phenol derivatives by Desulfobacterium phenolicum sp. nov. Arch Microbiol 146: 177-180.

Beller HR, Spormann AM, Sharma PK, Cole JR, Reinhard M. (1996). Isolation and characterization of a novel toluene-degrading, sulfate-reducing bacterium. Appl Environ Microbiol 62: 1188-1196.

Burland SM, Edwards EA. (1999). Anaerobic benzene biodegradation linked to nitrate reduction. Appl Environ Microbiol 65: 529-533.

Chakraborty R, Coates JD. (2004). Anaerobic degradation of monoaromatic hydrocarbons. Appl Microbiol Biotechnol 64: 437-446.

Coates JD, Bhupathiraju VK, Achenbach LA, McInerney MJ, Lovley DR. (2001a). Geobacter hydrogenophilus, Geobacter chapellei and Geobacter grbiciae, three new, strictly anaerobic, dissimilatory Fe(III)-reducers. Int J Syst Evol Microbiol 51: 581-588.

Coates JD, Chakraborty R, Lack JG, O’Connor SM, Cole KA, Bender KS et al. (2001b). Anaerobic benzene oxidation coupled to nitrate reduction in pure culture by two strains of Dechloromonas. Nature 411: 1039-1043.

Collins MD, Lawson PA, Willems A, Cordoba JJ, Fernandez-Garayzabal J, Garcia P et al. (1994). The phylogeny of the genus Clostridium: proposal of five new genera and eleven new species combinations. Int $J$ Syst Bacteriol 44: 812-826. 
Dean BJ. (1985). Recent findings on the genetic toxicology of benzene, toluene, xylenes and phenols. Mut Res 154: 153-181.

Eichinger J, Rauert W, Salvamoser J, Wolf M. (1980). Largevolume liquid scintillation counting of carbon-14. Radiocarbon 22: 417-427.

Heider J, Spormann AM, Beller HR, Widdel F. (1998). Anaerobic bacterial metabolism of hydrocarbons. FEMS Microbiol Rev 22: 459-473.

Jahn MK, Haderlein SB, Meckenstock RU. (2005). Anaerobic degradation of benzene, toluene, ethylbenzene, and $o$-xylene in sediment-free iron-reducing enrichment cultures. Appl Environ Microbiol 71: 3355-3358.

Jeon CO, Park W, Padmanabhan P, DeRito C, Snape JR, Madsen EL. (2003). Discovery of a bacterium, with distinctive dioxygenase, that is responsible for in situ biodegradation in contaminated sediment. Proc Natl Acad Sci 100: 13591-13596.

Kasai Y, Takahata Y, Manefield M, Watanabe K. (2006). RNA-based stable isotope probing and isolation of anaerobic benzene-degrading bacteria from gasolinecontaminated groundwater. Appl Environ Microbiol 72: 3586-3592.

Kazumi J, Caldwell ME, Suflita JM, Lovley DR, Young LY. (1997). Anaerobic degradation of benzene in diverse anoxic environments. Environ Sci Technol 31: 813-818.

Knoblauch C, Sahm K, Jorgensen BB. (1999). Psychrophilic sulfate-reducing bacteria isolated from permanently cold Arctic marine sediments: description of Desulfofrigus oceanense gen. nov., sp. nov., Desulfofrigus fragile sp. nov., Desulfofaba gelida gen. nov., sp. nov., Desulfotalea psychrophila gen. nov., sp. nov. and Desulfotalea arctica sp. nov. Int J Syst Bacteriol 49: 1631-1643.

Kuever J, Rainey FA, Widdel F. (2005). Class IV. Deltaproteobacteria class nov. In: Brenner DJ, Krieg NR, Staley JT, Garrity GM (eds). Bergey's Manual of Systematic Bacteriology. Springer: New York, NY, USA, pp 922-1144.

Lonergan DJ, Jenter HL, Coates JD, Phillips EJP, Schmidt TM, Lovley DR. (1996). Phylogenetic analysis of dissimilatory Fe(III)-reducing bacteria. J Bacteriol 178: 2402-2408.

Lovley DR, Coates JD, Woodward JC, Phillips EJP. (1995). Benzene oxidation coupled to sulfate reduction. Appl Environ Microbiol 61: 953-958.

Lovley DR, Giovannoni SJ, White DC, Champine JE, Phillips EJP, Gorby YA et al. (1993). Geobacter metallireducens gen. nov. sp. nov., a microorganism capable of coupling the complete oxidation of organic compounds to the reduction of iron and other metals. Arch Microbiol 159: 336-344.

Lovley DR, Phillips EJP. (1986). Organic matter mineralization with reduction of ferric iron in anaerobic sediments. Appl Environ Microbiol 51: 683-689.

Ludwig W, Strunk O, Westram R, Richter L, Meier H, Yadhukumar et al. (2004). ARB: a software environment for sequence data. Nucl Acids Res 32: 1363-1371.

Lueders T, Kindler R, Miltner A, Friedrich MW, Kaestner M. (2006). Identification of bacterial micropredators distinctively active in a soil microbial food web. Appl Environ Microbiol 72: 5342-5348.

Lueders T, Manefield M, Friedrich MW. (2004). Enhanced sensitivity of DNA- and rRNA-based stable isotope probing by fractionation and quantitative analysis of isopycnic centrifugation gradients. Environ Microbiol 6: $73-78$.

Madsen EL. (2006). The use of stable isotope probing techniques in bioreactor and field studies on bioremediation. Curr Opin Biotechnol 17: 92-97.

Mahmood S, Paton GI, Prosser JI. (2005). Cultivationindependent in situ molecular analysis of bacteria involved in degradation of pentachlorophenol in soil. Environ Microbiol 7: 1349-1360.

Manefield M, Whiteley AS, Griffiths RI, Bailey MJ. (2002). RNA stable isotope probing, a novel means of linking microbial community function to phylogeny. Appl Environ Microbiol 68: 5367-5373.

Meckenstock RU. (1999). Fermentative toluene degradation in anaerobic defined syntrophic cocultures. FEMS Microbiol Lett 177: 67-73.

Meckenstock RU, Safinowski M, Griebler C. (2004). Anaerobic degradation of polycyclic aromatic hydrocarbons. FEMS Microbiol Ecol 49: 27-36.

Padmanabhan P, Padmanabhan S, DeRito C, Gray A, Gannon D, Snape JR et al. (2003). Respiration of ${ }^{13} \mathrm{C}$-labeled substrates added to soil in the field and subsequent $16 \mathrm{~S}$ rRNA gene analysis of ${ }^{13} \mathrm{C}$-labeled soil DNA. Appl Environ Microbiol 69: 1614-1622.

Phelps CD, Kerkhof LJ, Young LY. (1998). Molecular characterization of a sulfate-reducing consortium which mineralizes benzene. FEMS Microbiol Ecol 27: 269-279.

Phelps CD, Young LY. (1999). Anaerobic biodegradation of BTEX and gasoline in various aquatic sediments. Biodegradation 10: 15-25.

Rabus R, Nordhaus R, Ludwig W, Widdel F. (1993). Complete oxidation of toluene under strictly anoxic conditions by a new sulfate-reducing bacterium. Appl Environ Microbiol 59: 1444-1451.

Radajewski S, Ineson P, Parekh NR, Murrell JC. (2000). Stable-isotope probing as a tool in microbial ecology. Nature 403: 646-649.

Robertson WJ, Bowman JP, Franzmann PD, Mee BJ. (2001). Desulfosporosinus meridiei sp. nov., a spore-forming sulfate-reducing bacterium isolated from gasolenecontaminated groundwater. Int J Syst Evol Microbiol 51: 133-140.

Rooney-Varga JN, Anderson RT, Fraga JL, Ringelberg D, Lovley DR. (1999). Microbial communities associated with anaerobic benzene degradation in a petroleumcontaminated aquifer. Appl Environ Microbiol 65: 3056-3063.

Schink B. (1997). Energetics of syntrophic cooperation in methanogenic degradation. Microbiol Mol Biol Rev 61: 262-280.

Schlötelburg C, von Wintzingerode F, Hauck R, Hegemann W, Göbel UB. (2000). Bacteria of an anaerobic 1,2dichloropropane-dechlorinating mixed culture are phylogenetically related to those of other anaerobic dechlorinating consortia. Int J Syst Evol Microbiol 50: 1505-1511.

Slobodkin A, Reysenbach AL, Mayer F, Wiegel J. (1997). Isolation and characterization of the homoacetogenic thermophilic bacterium Moorella glycerini sp. nov. Int J Syst Bacteriol 47: 969-974.

Sokolova TG, Kostrikina NA, Chernyh NA, Kolganova TV, Tourova TP, Bonch-Osmolovskaya EA. (2005). Thermincola carboxydiphila gen. nov., sp. nov., a novel anaerobic, carboxydotrophic hydrogenogenic bacterium from a hot spring of the Lake Baikal area. Int J Syst Evol Microbiol 55: 2069-2073. 
Stookey LL. (1970). Ferrozine-a new spectrophotometric reagent for iron. Anal Chem 42: 779-781.

Straub KL, Schink B. (2004). Ferrihydrite-dependent growth of Sulfurospirillum deleyianum through electron transfer via sulfur cycling. Appl Environ Microbiol 70: 5744-5749.

Szewzyk R, Pfennig N. (1987). Complete oxidation of catechol by the strictly anaerobic sulfate-reducing Desulfobacterium catecholicum sp. nov. Arch Microbiol 147: 163-168.

Ulrich AC, Edwards EA. (2003). Physiological and molecular characterization of anaerobic benzene-degrading mixed cultures. Environ Microbiol 5: 92-102.

Villemur R, Lanthier M, Beaudet R, Lepine F. (2006). The Desulfitobacterium genus. FEMS Microbiol Rev 30: 706-733.

Weiner JM, Lovley DR. (1998). Rapid benzene degradation in methanogenic sediments from a petroleum-contaminated aquifer. Appl Environ Microbiol 64: 1937-1939.

Weisburg WG, Barns SM, Pelletier DA, Lane DJ. (1991). $16 \mathrm{~S}$ ribosomal DNA amplification for phylogenetic study. J Bacteriol 173: 697-703.

Widdel F, Bak F. (1992). Gram-negative mesophilic sulfatereducing bacteria. In: Balows A, Trüper HG, Dworkin M, Harder W, Schleifer K-H (eds). The Prokaryotes. Springer: New York, NY, USA, pp 3352-3378.
Winderl C, Schaefer S, Lueders T. (2007). Detection of anaerobic toluene and hydrocarbon degraders in contaminated aquifers using benzylsuccinate synthase (bss $A$ ) genes as a functional marker. Environ Microbiol 9: 1035-1046.

Yi H, Schumann P, Chun J. (2007). Demequina aestuarii gen. nov., sp. nov., a novel actinomycete of the suborder Micrococcineae, and reclassification of Cellulomonas fermentans Bangara et al. 1985 as Actinotalea fermentans gen. nov., comb. nov. Int $J$ Syst Evol Microbiol 57: 151-156.

Yu C-P, Chu K-H. (2005). A quantitative assay for linking microbial community function and structure of a naphthalene-degrading microbial consortium. Environ Sci Technol 39: 9611-9619.

Zavarzina DG, Sokolova TG, Tourova TP, Chernyh NA, Kostrikina NA, Bonch-Osmolovskaya EA. (2007). Thermincola ferriacetica sp. nov., a new anaerobic, thermophilic, facultatively chemolithoautotrophic bacterium capable of dissimilatory Fe(III) reduction. Extremophiles 11: 1-7.

Zengler K, Richnow HH, Rosello-Mora R, Michaelis M, Widdel F. (1999). Methane formation from long-chain alkanes by anaerobic microorganisms. Nature 401: 466-469. 